\title{
PET-CT FINDINGS IN HIV-POSITIVE AND NEGATIVE PATIENTS WITH LOCALLY ADVANCED CERVICAL CANCER IN A SOUTH AFRICAN COHORT
}

H Simonds ${ }^{1}, \mathrm{MH}$ Botha ${ }^{2}, \mathrm{~A}$ Ellmann ${ }^{3}, \mathrm{JWarwick}^{3}$, A Doyruter $^{3}, \mathrm{~A} \mathrm{Neugut}^{4}, \mathrm{FH}$ Van der Merwe ${ }^{2}$, JS Jacobson ${ }^{4}$

Radiation Oncology ${ }^{1}$, Gynaecological Oncology ${ }^{2}$ and Nuclear Medicine ${ }^{3}$; Stellenbosch University \& Tygerberg Academic Hospital Mailman School of Public Health; Columbia University.

\section{Introduction}

PET-CT imaging is commonly used to identify nodal involvement in locally advanced cervical carcinoma, but its appropriateness for that purpose among HIV-positive patients has rarely been studied ${ }^{1,2}$.

\section{Objectives}

We conducted a study of the contribution of PET-CT to staging and stratification for treatment in HIV-negative and -positive women in a large cohort of patients with cervical cancer in a single institution in South Africa. Our objective was to evaluate if nodal involvement would be more prevalent in HIV-positive than in HIV-negative patients; and if PET-CT findings would lead to changes in radiotherapy fields or treatment intent.

\section{Methods}

We identified a cohort of consecutive cervical carcinoma patients, FIGO Stage IIB to IIIB, at our cancer centre who underwent a planning ${ }^{18}$ FDG PET-CT scan from January 2015 through December 2018. Patients were selected for PET-CT if deemed suitable for radical radiation by the multi-disciplinary team. The PET-CT and planning CT were performed using a Phillips Gemini Big Bore time-of-flight 16-slice PET/CT camera. The fused images were used to delineate target volumes.

Demographics, PET-CT findings, and subsequent treatment prescribed were recorded and compared by HIV status.

\begin{tabular}{r|llll}
\hline & $\begin{array}{l}\text { HIV-pos } \\
\text { N=86 }\end{array}$ & $\begin{array}{l}\text { HIV-neg } \\
\text { N=192 }\end{array}$ & $\begin{array}{l}\text { Cohort } \\
\text { N=278 }\end{array}$ & p-value \\
\hline IIB & $2(2.3 \%)$ & $7(3.6 \%)$ & $9(3.2 \%)$ & 0.34 \\
IIIA & 0 & $2(1.0 \%)$ & $2(0.7 \%)$ & \\
IIIB & $10(11.6 \%)$ & $22(11.5 \%)$ & $32(11.5 \%)$ & \\
IIIC1r & $28(32.6 \%)$ & $76(39.6 \%)$ & $104(37.4 \%)$ & \\
\hline IIIC2r & $25(29.1 \%)$ & $52(27.1 \%)$ & $77(27.7 \%)$ & \\
\hline IVB & $21(24.4 \%)$ & $33(17.2 \%)$ & $54(19.4 \%)$
\end{tabular}

Table 1 Final FIGO stage (2018) by HIV status

\section{$\underline{\text { Results }}$}

Over a 4-year period, 278 patients, 192 HIV-negative (69.1\%) and 86 HIV-positive (30.9\%), met the inclusion criteria. HIVpositive patients had a median CD4 count of 475 cells/ $\mu$ I (IQR 307-612 cells/ $\mu \mathrm{l}$ ) and were significantly younger than the HIVnegative patients (median age 41 years v.s.50 years; $p<0.01$ ).
More than $80 \%$ of patients had pelvic nodal involvement, and more than $40 \%$ had uptake in common iliac and/or para-aortic nodes. Nodal involvement was not associated with HIV status. Fifty-four patients (19.4\%) had at least one site of distant metastatic disease.

Overall, 235 patients (84.5\%) were upstaged following PET-CT staging scanning. Upstaging was not associated with HIV status (HIV-negative $83.9 \%$ vs HIV-positive 87.2\%; $p=0.47$ ). Table 1

Ten patients who did not return for radiotherapy and were excluded from the analysis. Following PET-CT scanning, treatment intent changed for 124 patients (46.3\%): $53.6 \%$ of HIV-positive patients and $42.9 \%$ of HIV-negative patients $(p=0.11)$. Table 2

\begin{tabular}{l|llll}
\hline & $\begin{array}{l}\text { HIV-pos } \\
n=84\end{array}$ & $\begin{array}{l}\text { HIV-neg } \\
n=184\end{array}$ & $\begin{array}{l}\text { All } \\
n=268 *\end{array}$ & P value \\
\hline $\begin{array}{l}\text { Std Fraction } \\
\text { EBRT }\end{array}$ & $39(46.4 \%)$ & $105(57.1 \%)$ & $144(53.7 \%)$ & 0.11 \\
$\begin{array}{l}\text { Extended field } \\
\text { EBRT }\end{array}$ & $24(28.6 \%)$ & $41(22.3 \%)$ & $65(24.3 \%)$ & \\
$\begin{array}{l}\text { Hypofrac } \\
\text { EBRT }\end{array}$ & $12(14.3 \%)$ & $15(8.2 \%)$ & $27(10.1 \%)$ & \\
$\begin{array}{l}\text { Palliative } \\
\text { EBRT }\end{array}$ & $9(10.7 \%)$ & $23 .(12.5 \%)$ & $32(11.9 \%)$ & \\
\hline
\end{tabular}

Table 2 Treatment intent by HIV status Discussion

In our cohort, many patients were upstaged following PET-CT. However no difference was found between HIV-negative and positive patients, similar to reports in the literature. ${ }^{3-6}$

The prevalence of pelvic and/or para-aortic node positivity on PET-CT was higher among our patients (both HIV-positive and negative) than has been reported in international data on HIVnegative populations ${ }^{7-9}$. Our study population was a selected high-risk group in that many had clinical stage III disease, most likely due to delayed access to healthcare.

The main purpose of integrating PET-CT into the staging algorithm in our cohort was to identify patients who needed a change in the planned radiation fields or in treatment intent. Nearly half of our patients were allocated to palliative treatment, hypofractionated radiotherapy, or extended field radiotherapy. This allows more appropriate use of resources and appropriate care for our patient cohort.

\section{Conclusion}

We found no differences between HIV-positive or HIV-negative patients in nodal involvement or occult metastases, and PET-CT imaging did not lead to, or justify, treatment differences between the two groups. Future studies will evaluate survival and correlation of upstaging with outcome. 